- draft -

not to be cited

\title{
Predecessor Items and Performance Level
}

Paper presented at the European Conference on Educational Research, Edinburgh, 20-23 September 2000

Symposium

"TIMSS-R Findings in a National Perspective"

Pauline Vos, Wilmad Kuiper \& Klaas Bos

University of Twente

Faculty of Educational Technology

Department of Curriculum Technology

P.O. Box 217, 7500 AE Enschede, Netherlands

E-mail: <f.p.vos@edte.utwente.nl> 
- draft -

not to be cited

\title{
Predecessor Items and Performance Level
}

\author{
Pauline Vos, Wilmad Kuiper \& Klaas Bos \\ University of Twente, faculty of Educational Technology, Enschede, Netherlands
}

\begin{abstract}
:
In the Netherlands the question arose whether the difficulty of an item in a cognitive test would affect the performance of students on the ensuing items. Emotional disturbance due to failure could interfere with achievement.

The rotation of item clusters in the TIMSS and TIMSS-R testing design allows to quantify effects of item sequencing. Evidence from TIMSS and TIMSS-R data in the Netherlands suggests that a considerable number of students, unable to master a certain item, is discouraged by their failure. The negative effect on performances of the following item is measurable.
\end{abstract}

\section{Introduction}

In 1995 two carefully sampled groups of 14-year-old Dutch students participated in a project which included a test of their mathematics achievements. Both groups received a different test, but there was an overlap of test items with the purpose of comparing the outcomes of the two tests. These items originated from the Third International Mathematics and Science Study (TIMSS) achievement test for Population 2 (grade 7 and 8). It was expected that no significant difference would occur in the performances of the two student groups on the overlapping items.

Yet, the differences in the performances of the two student groups were statistically significant. This could not be ascribed to differences in the two samples that were representing the same population. In no way did they differ in social-economic backgrounds, in gender ratio, in age nor in circumstances under which both tests were administered. It was suggested that the only parameter that could have influenced the differences was the sequence of the items (Kuiper, Bos \& Plomp, 1997; 2000).

Further study asserted that the differences in the levels of success on an item could be correlated to the differences in the levels of success on the immediate preceding item. The emerging research question became: Is the performance level on a single item in a cognitive test affected by the level of difficulty of the preceding item? The passage from a difficult item to the next would show a disturbance in the performances on the latter. Whenever only only a few students mastered a preceding item, the percentage of correct scores on the following item would be lower than the performance on the 
same item of the control group. This evidence is described below in the first section "TIMSS and the National Option Test in the Netherlands".

To replicate these findings, a further study was carried out. It makes use of data from the TIMSS and TIMSS-R achievement test. The backbone for this study is the TIMSS test design, whereby the test is assembled in eight different test booklets. Clusters of items are rotated through the booklets, resulting in eight different sequences of clusters of items. The study investigates the performances of students on these different sequences. The design of this study, the statistics and results constitute the core of this paper.

At the end conclusions and points for further discussion are presented.

\section{TIMSS and the National Option Test in the Netherlands}

In 1995 TIMSS was carried out in the Netherlands. As described in Kuiper, Bos \& Plomp (1997, 1999, 2000), in the preparations of this project the national advisory committee discussed the discrepancies between the Dutch mathematics curriculum and the mathematics items of the TIMSS achievement test. The items from the international test were conceived to be unfamiliar to the students and TIMSS would not do justice to their abilities. As a result, an additional mathematics test was designed for the higher grade of Population 2 (grade 8), to analyse whether the international TIMSS test for mathematics would be a fair test to the Dutch students. This test was named NOT, National Option Test, and would contain test items that would match the intended curriculum of the students. For comparison purposes an overlap between the two tests (TIMSS and NOT) was required. Therefore, curriculum experts selected 16 items from the TIMSS achievement test with the criterion of matching the national intended curriculum for mathematics. These 16 anchor items were thus the common items in NOT and TIMSS. In NOT they were joined by newly developed items comparable to the ones that students would see in their daily mathematics practice at school, while in TIMSS they were surrounded by items which did not match well with the intended curriculum.

The TIMSS achievement test was administered through eight different test booklets that were randomly issued to the students of the participating classes. The additional sample of students for the NOT was intertwined with the TIMSS sample in the following way. The 16 selected items and the new "Dutch items" were included into a ninth test booklet with a comparable colourful appearance as the eight TIMSS booklets. Thus, each participating school received nine instead of eight different versions of test booklets, to randomly administer among their selected class of grade 8 students. The students were only informed about the international TIMSS project and they were unaware of the differences between the NOT booklet and the others.

To compare NOT with TIMSS, the performances on the 16 common items in both tests were crucial. It was expected, that the two subsamples from the within school sample (the NOT students and the TIMSS students) would show equivalent performances on these common items, as the students were from the same schools, from the same classes, from the same backgrounds etc. Even the time of testing was exactly the same, as the testing of TIMSS and NOT took place during the same sessions.

Yet significant differences in the performances of the two student groups occurred. This is reported in Table 1 (copied from Kuiper, Bos \& Plomp, 1997). The first 
column shows the 16 anchor items which appeared in this order in the NOT test booklet. The second column displays the proportion of correct answers (in percent) on these 16 items by the sample of 239 NOT students. The last column displays the proportion of correct answers of their TIMSS counterparts who received one of the eight TIMSS test booklets. Because some of the 16 items appeared in more than one TIMSS booklet, the total number of students across items varies in this column.

Table 1.

Percentages of Dutch students giving the correct answer on common items in TIMSS and NOT (p-values).

\begin{tabular}{c|cc} 
Item number & $\begin{array}{c}\text { NOT students } \\
\text { \% correct }(\mathrm{n}=239)\end{array}$ & $\begin{array}{c}\text { TIMSS students } \\
\text { \% correct }(212 \leq n \leq 1954)\end{array}$ \\
\hline 01 & 71 & 66 \\
02 & 72 & 71 \\
03 & 70 & 67 \\
04 & 83 & 78 \\
05 & 67 & 61 \\
06 & 92 & 84 \\
07 & 55 & 40 \\
08 & 63 & 67 \\
09 & 75 & 72 \\
10 & 73 & 63 \\
11 & 85 & 82 \\
12 & 58 & 52 \\
13 & 84 & 82 \\
14 & 80 & 70 \\
15 & 78 & 69 \\
16 & 67 & 57
\end{tabular}

As can be observed, the differences in the proportion of correct scores by the two student groups are considerable. Not all differences are significant, but some of them are extreme (items $07,10,14,16$ ) where as much as $10 \%$ differences occur. In most cases the NOT students performed better, with the exception of item 08.

As the two samples were drawn from the same population, they were fully equivalent in age, gender ratio, social-economic status, etc. These factors could not have caused the significant differences to occur. It appeared that only item environment could have influenced the differences in scores. It was possible that the mixing of the 16 common items with "unfamiliar" items caused the lower achievement of the TIMSS students. The NOT students only received items which matched with their curriculum and they might have felt more comfortable with these. The only case where the NOT students showed a lower achievement was in the specific case of item 08. It was preceded by item 07, which was very hard, if the percentage of correct scores is taken as a measure. Item 07 had the lowest percentage of correct scores in both groups. This triggered the assumption, that the immediate preceding item might have an impact on the performance of the next item.

To understand the impact of item sequence, for each item the percentages correct of the preceding item was calculated. The percentage of correct answers on these preceding items was taken as a measure of difficulty (Wood, 1991). 
For the NOT students the items appeared in the test booklet in the order as stated in Table 1 . As a consequence, item 01 had no predecessor, as it was the very first item the students encountered in the testing session.

The TIMSS students who received one of the eight TIMSS test booklets had other preceding items than the NOT students, with varying difficulty and topics. These items could even not be mathematics items, but science items.

In all 16 cases, the anchor items and their predecessors were contained within the same clusters of items in the TIMSS booklets. Therefore all TIMSS students had the same item passage, even if the rotation of clusters in their booklets differed.

In Table 2 for each of the 16 common test items in NOT and TIMSS, the percentages of correct scores are given (equal to Table 1), but extra columns for the percentages correct on the predecessor items are added.

Table 2:

Dutch students' scores on the 16 common items in NOT and TIMSS and the preceding items thereof, and differences in the scores between TIMSS and NOT.

\begin{tabular}{|c|c|c|c|c|c|c|}
\hline \multirow[b]{2}{*}{$\begin{array}{l}\text { Item } \\
\text { number }\end{array}$} & \multicolumn{2}{|c|}{$\begin{array}{l}\text { NOT students } \\
\quad(\mathrm{n}=239)\end{array}$} & \multicolumn{2}{|c|}{$\begin{array}{l}\text { TIMSS students } \\
(212 \leq n \leq 1954)\end{array}$} & \multicolumn{2}{|c|}{$\begin{array}{l}\text { Differences between } \\
\text { NOT and TIMSS }\end{array}$} \\
\hline & $\begin{array}{l}\% \text { correct } \\
\text { on item }\end{array}$ & $\begin{array}{c}\% \text { correct on } \\
\text { preceding item }\end{array}$ & $\begin{array}{l}\% \text { correct } \\
\text { on item }\end{array}$ & $\begin{array}{l}\% \text { correct on } \\
\text { preceding item }\end{array}$ & $\begin{array}{c}\text { \% diff on } \\
\text { common item }\end{array}$ & $\begin{array}{c}\% \text { diff on } \\
\text { preceding } \\
\text { items }\end{array}$ \\
\hline 01 & 71 & (no predecessor) & 66 & 65 & 5 & N/A \\
\hline 02 & 72 & 71 & 71 & 39 & 1 & 32 \\
\hline 03 & 70 & 72 & 67 & 77 & 3 & -5 \\
\hline 04 & 83 & 70 & 78 & 67 & 5 & 3 \\
\hline 05 & 67 & 83 & 61 & 53 & 6 & 30 \\
\hline 06 & 92 & 67 & 84 & 70 & 8* & -3 \\
\hline 07 & 55 & 92 & 40 & 61 & $15^{*}$ & 31 \\
\hline 08 & 63 & 55 & 67 & 74 & -4 & -19 \\
\hline 09 & 75 & 63 & 72 & 93 & 3 & -30 \\
\hline 10 & 73 & 75 & 63 & 27 & $10^{*}$ & 48 \\
\hline 11 & 85 & 73 & 82 & 62 & 3 & 11 \\
\hline 12 & 58 & 85 & 52 & 48 & 6 & 37 \\
\hline 13 & 84 & 58 & 82 & 57 & 2 & 1 \\
\hline 14 & 80 & 84 & 70 & 54 & $10^{*}$ & 30 \\
\hline 15 & 78 & 80 & 69 & 63 & 9* & 17 \\
\hline 16 & 67 & 78 & 57 & 59 & $10^{*}$ & 19 \\
\hline average & 73.3 & 73.7 & 67.6 & 60.6 & & \\
\hline
\end{tabular}

On the right-hand side of Table 2, the differences between the percentages of NOT students and TIMSS students are given for each of the 16 anchor items. A positive number indicates that the NOT students had a higher result, a negative number indicates that the TIMSS students had a higher result. Significant differences received an asterisk. Also the differences between the percentages of NOT students and TIMSS students for the preceding items are given.

Considerable contrasts can be observed. E.g. item 02 had a very difficult preceding item for the TIMSS students as only 39\% of them was able to give the correct answer. As a result, the differences in the last column are high. Here it must be kept in mind that each predecessor item for the NOT students was one that was considered to be 
appropriate to the Dutch intended mathematics curriculum, while the predecessor item for the TIMSS students were from a wider range of topics and cognitive levels.

In Table 2 also the average percentage of correct scores on the 16 common items have been calculated. On average $73,3 \%$ of the NOT students were able to give a correct answer on each of the 16 common anchor items, against only $67.7 \%$ of their counterparts, the TIMSS students. But the predecessor items for the latter were on average also more difficult with an average percentage correct of only $60,6 \%$ against $73.7 \%$ for the NOT students.

As the first common item 01 did not have a predecessor for the NOT students, this item is excluded from further analysis. To visualise the information of Table 2, a scatter diagram is drawn for the data in its two last columns. In Figure1 the variables dp(pred) and dp(succ) indicate the differences in the percentages of correct scores on the predecessor and the successor items, with the 15 anchor items which appeared both in the NOT test and the TIMSS test being the successors.

Figure 1.

Scatter diagram of differences in p-values between NOT students and TIMSS students on predecessor items and the (common) successor items.

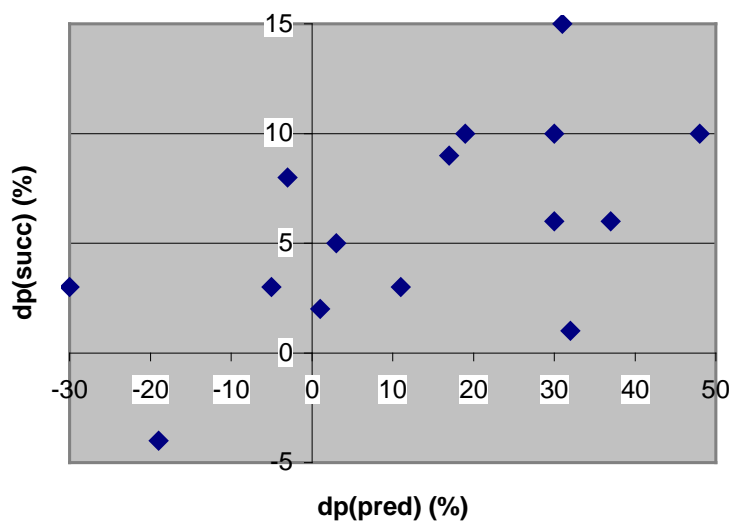

The scatter diagram suggests a trend: a higher difference between the predecessor items tends to lead to a higher difference on the (common) successor item. The correlation $\mathrm{r}=0.583$ is significant (with $\mathrm{p}<0.05$, two-tailed) and supports this assumption. If a group is successful in finding the correct answer on the predecessor item (their percentage correct is high), then their performances will be relatively higher on the ensuing item when compared to a control group. The lower percentage correct on the predecessor item of the control group could reflect that they had a more difficult predecessor item. It could be interpreted that students, who struggled with one item, could be emotionally affected. This would disturb the performance on the next item and fewer students would be successful in finding the correct answer.

From the above observations in comparing NOT and TIMSS data, a research question emerged: "Is the performance level on a single item in a cognitive test affected by the level of difficulty of the preceding item?" Scattered literature supported this (Huck \&Bowers, 1972; Hodson, 1984, 1987; Carlson \& Ostrosky, 1992). 


\section{Design of the study, using the TIMSS and TIMSS-R database}

To investigate the research question, an appropriate experiment would be, to create two equivalent student groups $\mathrm{A}$ and $\mathrm{B}$ and give these groups nearly the same test. Both tests would contain the same items with the single difference that the item sequence starts with a difficult item for group A and it starts with an easy item for group B. Will groups A and B show significant differences in percentages of correct scores on the common items?

As will be explained below, the TIMSS achievement test included this experiment and TIMSS-R replicated it. To apply the TIMSS and TIMSS-R data, the research question had to be limited to: Is performance on a single mathematics multiple choice item by Dutch grade 8 students in a test affected by the level of difficulty of the immediate preceding mathematics item?

Adams \& Gonzales (1996) describe the test design of TIMSS for Population 2 (and its replication TIMSS-R) in detail. More than 200 test items were included in the TIMSS achievement test, covering a wide range of topics and levels. This number was considered far too high for one test session of 90 minutes. Thus, the test items were distributed over eight test booklets, each containing a distinct set of items. Another advantage of eight different test booklets was that the practice of students' copying answers from their neighbours would be minimal. To arrange the items, they were grouped in clusters of approximately 12 items, of which 6 would be mathematics items followed by 6 science items (or in reversed order: first 6 science items, then 6 math items). The clusters were named alphabetically A, B, C etc through $\mathrm{Z}$. A rotation scheme was created to divide the clusters over the eight different test booklets, as given in Table 4. The arrangement was made in a way, that all students would do one common cluster (A) and that many clusters (B-H and T-Y) would appear in two different booklets.

Table 4.

The order of item clusters in the eight TIMSS test booklets (from: Adams \& Gonzales, 1996).

\begin{tabular}{|l|l|l|l|l|l|l|l|l|}
\hline \multirow{2}{*}{$\begin{array}{l}\text { Cluster } \\
\text { Order }\end{array}$} & \multicolumn{6}{l}{ TIMSS test booklet number } \\
\cline { 2 - 9 } & 1 & 2 & 3 & 4 & 5 & 6 & 7 & 8 \\
\hline $1^{\text {st }}$ & $\mathrm{B}$ & $\mathrm{C}$ & $\mathrm{D}$ & $\mathrm{E}$ & $\mathrm{F}$ & $\mathrm{G}$ & $\mathrm{H}$ & $\mathrm{B}$ \\
$2^{\text {nd }}$ & $\mathrm{A}$ & $\mathrm{A}$ & $\mathrm{A}$ & $\mathrm{A}$ & $\mathrm{A}$ & $\mathrm{A}$ & $\mathrm{A}$ & $\mathrm{A}$ \\
$3^{\text {rd }}$ & $\mathrm{C}$ & $\mathrm{D}$ & $\mathrm{E}$ & $\mathrm{F}$ & $\mathrm{G}$ & $\mathrm{H}$ & $\mathrm{B}$ & $\mathrm{Q}$ \\
$4^{\text {th }}$ & $\mathrm{S}$ & $\mathrm{W}$ & $\mathrm{T}$ & $\mathrm{X}$ & $\mathrm{U}$ & $\mathrm{Y}$ & $\mathrm{V}$ & \\
\hline \multicolumn{7}{|l|}{ Break } \\
\hline $5^{\text {th }}$ & $\mathrm{E}$ & $\mathrm{F}$ & $\mathrm{G}$ & $\mathrm{H}$ & $\mathrm{B}$ & $\mathrm{C}$ & $\mathrm{D}$ & $\mathrm{R}$ \\
$6^{\text {th }}$ & $\mathrm{I}$ & $\mathrm{J}$ & $\mathrm{K}$ & $\mathrm{L}$ & $\mathrm{M}$ & $\mathrm{N}$ & $\mathrm{O}$ & $\mathrm{P}$ \\
7 th & $\mathrm{T}$ & $\mathrm{X}$ & $\mathrm{U}$ & $\mathrm{Y}$ & $\mathrm{V}$ & $\mathrm{Z}$ & $\mathrm{W}$ & \\
\hline
\end{tabular}

For our purposes we searched for a common cluster in different booklets. This cluster needed to be preceded by differing clusters in each booklet. E.g. cluster $\mathrm{T}$ appeared in booklets 1 and 3 . In booklet 1 it was preceded by cluster I, while in booklet 3 it was preceded by cluster E. Thus, item passages from I12-T01 and E12-T01 would give the comparison. But the position within the testing session of cluster $\mathrm{T}$ in these two booklets was different (before and after the break). This could disturb the equal testing conditions (e.g. students could be more tired in the second half of the test). 
All students were to see cluster A in the second position of the test, and different clusters in the respective eight test booklets preceded this cluster. With cluster B appearing in both booklet 1 and 8 , there were seven different preceding clusters $(B, C$, D, E, F, G and H). Thus item A01 seemed to be a proper candidate for analysis.

To control equal testing conditions further, also the subject areas and difficulty level of the test items were considered. In Table 5 the subject areas (mathematics or science) for the first 15 items of each booklet are discerned. Items which could be considered as extremely hard (only less than $50 \%$ of the students could find a correct answer) are indicated with a “\#” .

As Dutch students are mostly exposed to mono-subject tests, it was preferred that the passage from one cluster to the next should be regular for them. The first six items of cluster A were mathematics items. The starting clusters C, E and G in booklets 2, 4 and 6 respectively, contained six science items at the end before the passage to item A01. This change of subject in the cluster passage was considered inappropriate for analysis. It could disturb equal testing conditions (e.g. some students who enjoy doing science, can drop their enthusiasm when they see the successor maths item A01). Students who had completed clusters B, D, F and H (in booklets 1, 3, 5, 7, 8) were all to continue without subject shift smoothly with common item A01.

Yet the students who worked on booklet 5 would have some extremely difficult items before the passage to A01 was to happen. Anticipating on disturbances by item F11, this group was also excluded from analysis.

Table 5.

Sequence of the first 15 items in each TIMSS test booklet, by subject (science=dark, mathematics= untainted), and difficulty (\# = extremely hard item).

The arrows indicate the selected passages to item A01.

\begin{tabular}{|c|c|c|c|c|c|c|c|c|c|c|c|c|c|c|c|c|}
\hline $\begin{array}{l}\text { Booklet } \\
\text { number }\end{array}$ & \multicolumn{13}{|c|}{ Sequence of items } & \multicolumn{3}{|c|}{ Common cluster A } \\
\hline 1 & B01 & B02 & $\frac{\text { B03 }}{\#}$ & B04 & B05 & B06 & B07 & B08 & B09 & B10 & B11 & B12 & $\rightarrow$ & A01 & A02 & A03 \\
\hline 2 & $\mathrm{C} 01$ & $\mathrm{C} 02$ & $\mathrm{C} 03$ & $\mathrm{C} 04$ & $\mathrm{C} 05$ & $\mathrm{C} 06$ & $\frac{\mathrm{C} 07}{\#}$ & $\mathrm{C} 08$ & $\mathrm{C} 09$ & $\mathrm{C} 10$ & C11 & $\mathrm{C} 12$ & & A01 & A02 & A03 \\
\hline 3 & $\frac{\text { D01 }}{\#}$ & D02 & $\frac{\text { D03 }}{\#}$ & D04 & D05 & D06 & D07 & D08 & D09 & D10 & D11 & D12 & $\rightarrow$ & A01 & A02 & A03 \\
\hline 4 & E01 & $\begin{array}{c}\text { E02 } \\
\#\end{array}$ & E03 & $\begin{array}{c}\text { E04 } \\
\#\end{array}$ & E05 & E06 & $\frac{\mathrm{E} 07}{\#}$ & E08 & E09 & E10 & E11 & E12 & & A01 & A02 & A03 \\
\hline 5 & F01 & F02 & F03 & F04 & F05 & F06 & $\begin{array}{c}\mathrm{F} 07 \\
\#\end{array}$ & F08 & F09 & F10 & $\begin{array}{c}\mathrm{F} 11 \\
\#\end{array}$ & F12 & & A01 & A02 & A03 \\
\hline 6 & G01 & G02 & G03 & G04 & G05 & G06\# & G07 & G08 & G09 & $\frac{\mathrm{G} 10}{\#}$ & $\frac{\text { G11 }}{\#}$ & G12 & & A01 & A02 & A03 \\
\hline 7 & H01 & H02 & $\mathrm{H} 03$ & H04 & $\underset{\#}{\mathrm{H} 05}$ & H06 & H07 & H08 & H09 & H10 & H11 & H12 & $\rightarrow$ & A01 & A02 & A03 \\
\hline 8 & B01 & B02 & $\frac{\text { B03 }}{\#}$ & B04 & B05 & B06 & B07 & B08 & B09 & B10 & B11 & B12 & $\rightarrow$ & A01 & A02 & A03 \\
\hline
\end{tabular}

After this selection, we remained with 4 equivalent samples of students, who worked on booklets 1, 3, 7 and 8 and the percentage of correct scores on item A01 would be correlated with the percentages correct of the preceding item. Both the Dutch data from TIMSS in 1995 (Kuiper, Bos \& Plomp, 1997) and TIMSS-R in 1999 (Bos \& Vos, in preparation) would be subject to analysis. 


\section{Data from TIMSS and TIMSS-R}

First we illustrate how the performance of two equivalent groups of students can be visualised when they have been given the same sequence of test items. With the two student groups 1 and 8 (who received the booklets 1 and 8 respectively), their first two clusters of items were equal (first cluster B, then cluster A). Their performance on the sequence of items did not differ significantly. Figure 2 displays for both groups the percentages of students who had given the correct answers on the 24 items of starting cluster B followed cluster A.

As can be seen, some items were easy with more than $90 \%$ of the students finding the correct answer (items B01, B04, B06). One item was extremely difficult as less than $40 \%$ of the students were able to find the correct answer (item B03).

Looking at the differences between the two student groups, slight fluctuations occur. These are insignificant in $96 \%$ of the cases (23 out of the 24 items) in two-tailed testing at 5\% level. The exception is item B10. When testing at the $1 \%$-level all differences are insignificant.

Figure 2.

Line diagram of the proportion correct (\%) of two different student groups from TIMSS working on the same sequence of items.

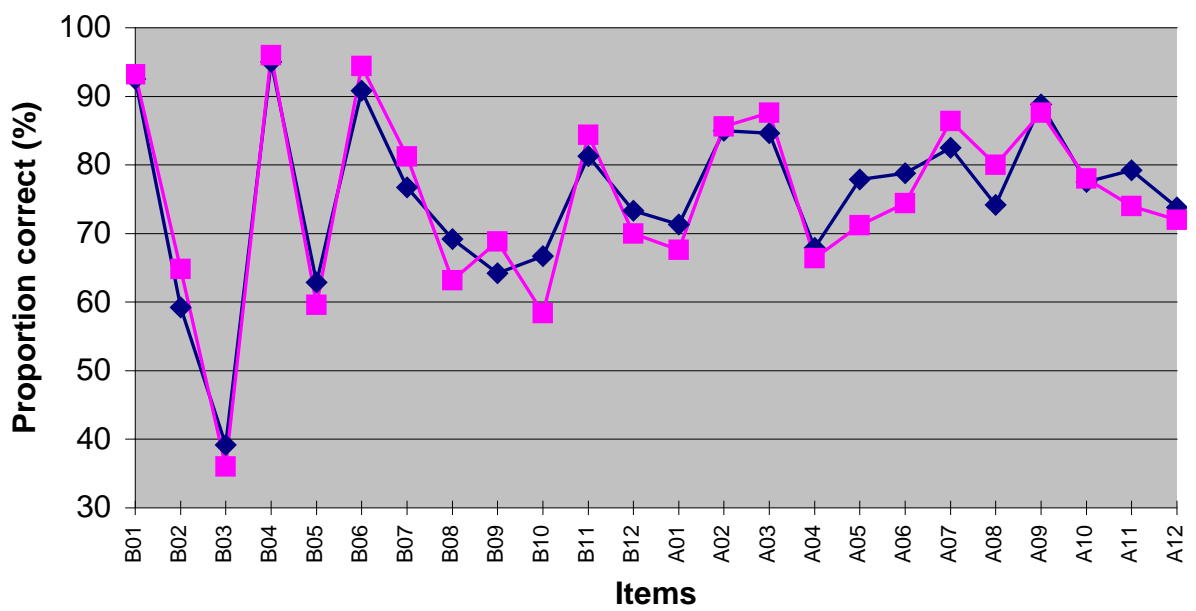

$\checkmark$ Group nr.1 Group nr.8

The sharp lines in Figure 2 are to be perceived with a bandwidth and the overlap between the two belts is substantial. Remarkable is that the two student groups take turns in outperforming each other. The average difference is almost nihil.

The student groups 1 and 8 had the starting cluster B. The other two samples of students (groups 3 and 7) had starting clusters $\mathrm{D}$ and $\mathrm{H}$ respectively, before proceeding to the common cluster for all four groups (cluster A). The performances on the first 16 test items, 12 from the differing starting clusters and 4 from the common second cluster, are given in Table 6a (for TIMSS) and Table 6b (for TIMSS-R). Because of the difference in items, the performances on the first 12 items are totally diverse. Only the performances of the student groups 1 and 8 who received the same starting cluster B are comparable, as already depicted in Figure 2 (for TIMSS). From the $13^{\text {th }}$ test item onwards, which is the first common item A01, all 
students groups have the same items. It is here, were all student groups should show comparable percentages.

Table 6a.

P-values (in \%) of four TIMSS student groups, for the first 16 items of the test (12 of the starting cluster and then common 4 items from cluster A).

\begin{tabular}{c|c|c|c|c}
\multirow{2}{*}{} & \multicolumn{4}{|c}{$\begin{array}{c}\text { Student group's number (n students) } \\
\text { First cluster of items, preceding cluster A }\end{array}$} \\
\cline { 2 - 5 } Item name & $1(240)$ & $3(251)$ & $7(243)$ & $8(250)$ \\
B & D & H & B \\
\hline (..)01 & 92.5 & $43.8^{\#}$ & 74.1 & 93.2 \\
(..)02 & 59.2 & 86.5 & 91.4 & 64.8 \\
(..)03 & $39.2^{\#}$ & $47.4^{\#}$ & 93.0 & $36.0^{\#}$ \\
(..)04 & 95.0 & 70.5 & 51.9 & 96.0 \\
(..)05 & 62.9 & 86.1 & $21.0^{\#}$ & 59.6 \\
(..)06 & 90.8 & 76.1 & 62.1 & 94.4 \\
(..)07 & 76.7 & 64.9 & 82.3 & 81.2 \\
(..)08 & 69.2 & 68.1 & 91.4 & 63.2 \\
(..)09 & 64.2 & 86.1 & 96.7 & 68.8 \\
(..)10 & 66.7 & 70.5 & 75.3 & 58.4 \\
(..)11 & 81.3 & 92.8 & 84.4 & 84.4 \\
(..)12 & 73.3 & 92.4 & 88.5 & 70.0 \\
A01 & 71.3 & 73.3 & 77.0 & 67.6 \\
A02 & 85.0 & 84.1 & 86.0 & 85.6 \\
A02 & 84.6 & 85.7 & 86.8 & 87.6 \\
A04 & 67.9 & 66.9 & 67.9 & 66.4 \\
\hline
\end{tabular}

\# extremely difficult item ( $\mathrm{p}<50 \%)$.

Table 6b.

P-values (in \%) of four TIMSS-R student groups, for the first 16 items of the test.

\begin{tabular}{|c|c|c|c|c|}
\hline \multirow[b]{2}{*}{ Item name } & \multicolumn{4}{|c|}{$\begin{array}{l}\text { Student group (n students) } \\
\text { First cluster of items, preceding cluster A }\end{array}$} \\
\hline & $\begin{array}{c}1(379) \\
\mathrm{B}\end{array}$ & $\begin{array}{c}3(369) \\
\mathrm{D}\end{array}$ & $\begin{array}{c}7(370) \\
H\end{array}$ & $\begin{array}{c}8(366) \\
\text { B }\end{array}$ \\
\hline$(. .) 01$. & 96.3 & $44.2^{\#}$ & 83.2 & 97.0 \\
\hline (...)02 & 64.1 & 75.6 & 94.6 & 65.3 \\
\hline (..)03 & $39.6^{\#}$ & $49.1^{\#}$ & 94.1 & $41.0^{\#}$ \\
\hline (...)04 & 96.0 & 62.9 & 52.4 & 96.2 \\
\hline (..)05 & 63.9 & 84.3 & $21.4^{\#}$ & 62.6 \\
\hline (..)06 & 92.6 & 75.9 & 71.9 & 91.5 \\
\hline (..)07 & 82.1 & 61.5 & 81.4 & 84.2 \\
\hline (..)08 & 69.7 & 67.2 & 93.5 & 69.9 \\
\hline (..)09 & 61.5 & 91.6 & 95.4 & 69.9 \\
\hline (..)10 & 77.3 & 76.4 & 71.9 & 73.8 \\
\hline (..)11 & 83.4 & 90.8 & 86.2 & 82.0 \\
\hline (..)12 & 81.0 & 93.0 & 87.8 & 80.9 \\
\hline A01 & 73.6 & 79.7 & 79.5 & 73.0 \\
\hline A02 & 89.5 & 88.1 & 85.7 & 85.2 \\
\hline A02 & 90.0 & 90.5 & 88.1 & 89.9 \\
\hline A04 & 70.7 & 68.6 & 71.9 & 72.7 \\
\hline
\end{tabular}


For visualisation, the data of the Tables $6 a$ and $6 \mathrm{~b}$ were each transformed into a line diagram and this is displayed in Figures 3a and 3b respectively.

Figure 3a.

P-values by four TIMSS student groups for the first 16 items of the test.
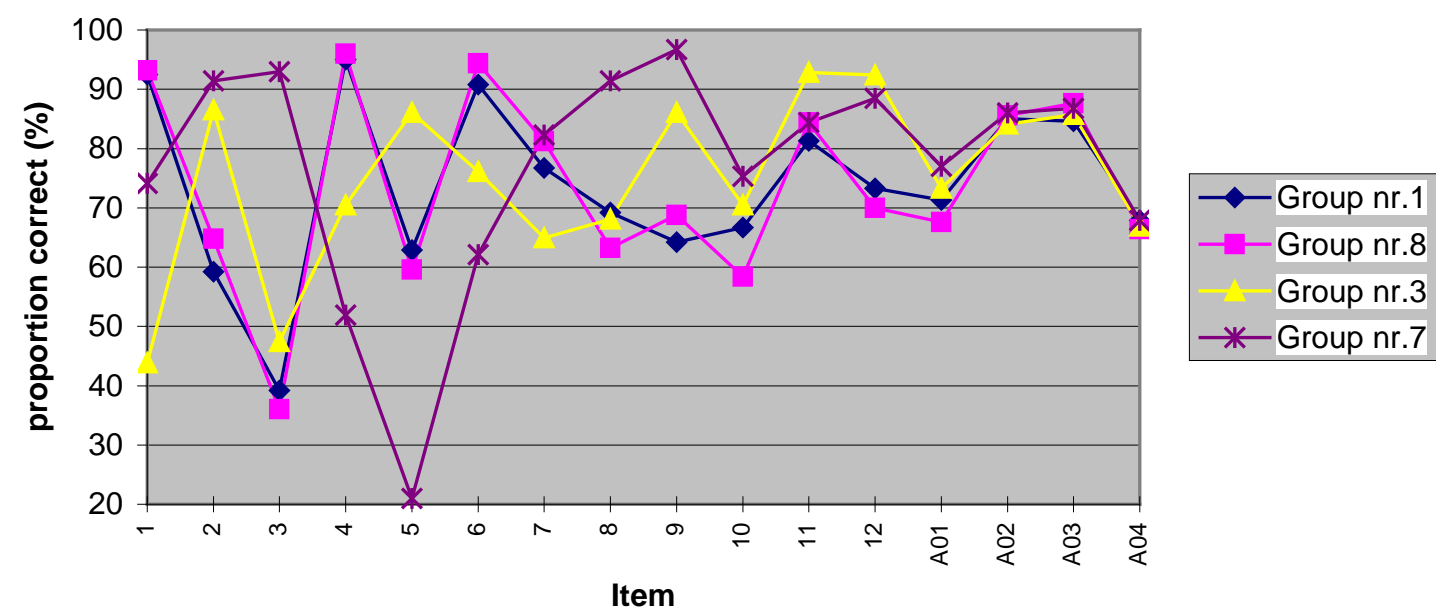

Figure 3b.

P-values by four TIMSS-R student groups for the first 16 items of the test.

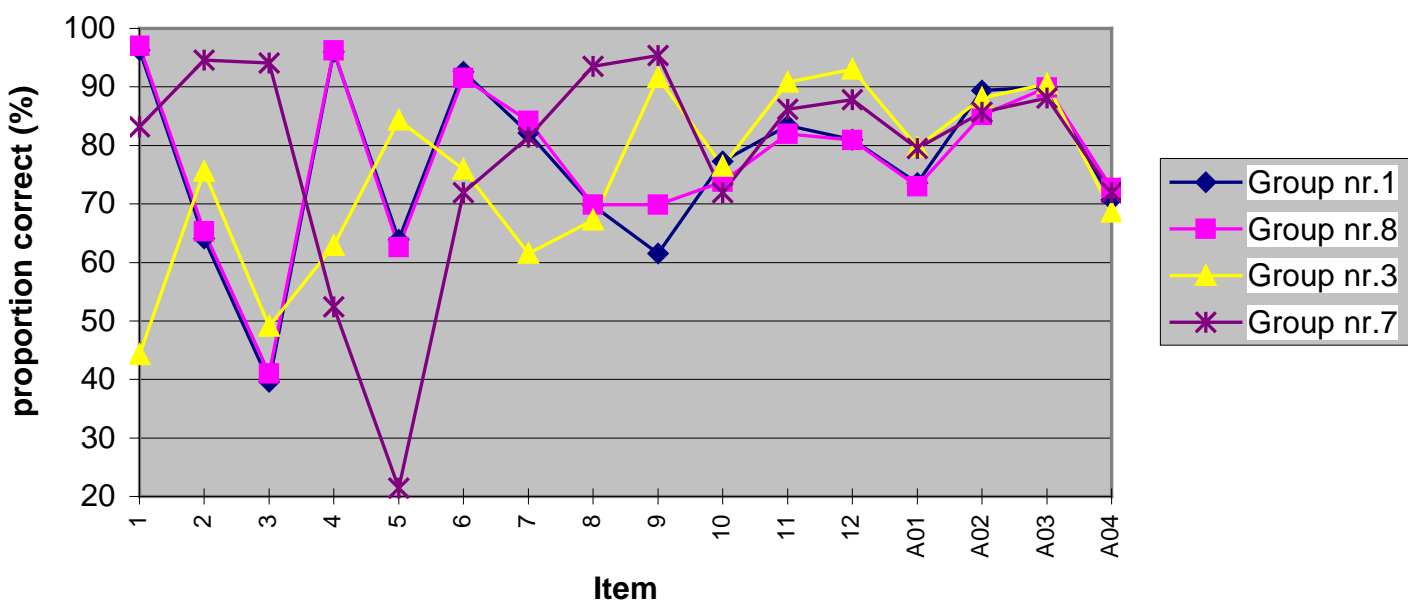

The left-hand part of both line diagrams is a cobweb because of the disparity in items: topics and difficulty levels were well mixed throughout the test booklets. Yet the general pattern, when comparing the two line diagrams of TIMSS and TIMSS-R, is surprisingly similar. Corresponding groups of 1995 (TIMSS) and 1999 (TIMSS-R) follow the same pattern of rise-and-fall. The students in 1999 seem to outperform the students of 1995 slightly. Also the closeness in the performances of the groups 1 and 8 who received the same items is eminent: the lines of groups 1 and 8 wind around each other in both figures.

On the right-hand side of the diagrams, from item A01 onwards, the four lines are converging into a narrow bundle. This is of course a consequence of the shared items for the four equivalent student groups. 
Both from Figure 3a and $3 b$ it is clear that the convergence of performance starts at item A01, but not fully. The different sequences of preceding items have a breaching impact on the first common item A01, but it only lasts for an instant. The first common item A01 shows differences, while the ensuing items A02, A03, etc. are not affected anymore. It also appears that the more difficult the preceding item, displayed by a lower percentage correct, the lower the performances on A01.

Is the disturbance on item A01 significant?

The largest differences occur between the performances on item A01 of the student groups 7 and 8 in TIMSS and groups 3 and 8 in TIMSS-R. Both differences are significant, when two-tailed tested at the $5 \%$ significance level. This supports our assertion: the predecessor item disturbs the performance on an item.

For further illustration, the range of percentages of the four student groups for the common items are given in Table 7a and 7b (for TIMSS and TIMSS-R respectively). These tables are copied from Tables $6 \mathrm{a}$ and $6 \mathrm{~b}$, only showing the preceding item of the differing item clusters ( $\mathrm{nr}$ 12) before the common items A01, A02, A03, A04 etc followed in the sequence. Three columns are added on the right, showing the range in which the percentages of each student group on any item stir. The large range for the percentages for the item (..)12 is a consequence of the difference in topics, cognitive levels, etc between these.

The small range for the items A02, A03 and A04 are tiny when compared to the range of item A01, which is $9.4 \%$ in TIMSS and 6.7\% in TIMSS-R.

Table 7a.

P-values for the items of cluster A by four TIMSS student groups, with one differing preceding item per group.

\begin{tabular}{c|cccc|ccc}
\multirow{2}{*}{$\begin{array}{c}\text { Item } \\
\text { number }\end{array}$} & \multicolumn{4}{|c|}{$\begin{array}{c}\text { Student group (n) } \\
\text { Preceding cluster }\end{array}$} & \multicolumn{3}{c}{ Range } \\
\cline { 2 - 8 } & $1(240)$ & $3(251)$ & $7(243)$ & $8(250)$ & & & \\
\hline (..)12 & 73.3 & 92.4 & 88.5 & 70.0 & 70.0 & 92.4 & 22.4 \\
A01 & 71.3 & 73.3 & 77.0 & 67.6 & 67.6 & 77.0 & $9.4 *$ \\
A02 & 85.0 & 84.1 & 86.0 & 85.6 & 84.1 & 86.0 & 1.9 \\
A03 & 84.6 & 85.7 & 86.8 & 87.6 & 84.6 & 87.6 & 3.0 \\
A04 & 67.9 & 66.9 & 67.9 & 66.4 & 66.4 & 67.9 & 1.5
\end{tabular}

Table 7b.

P-values for the items of cluster A by four TIMSS-R student groups, with one differing preceding item per group.

\begin{tabular}{c|cccc|ccc} 
& \multicolumn{4}{|c|}{$\begin{array}{l}\text { Student group (n) } \\
\text { Preceding cluster }\end{array}$} & \multicolumn{3}{c}{ Range } \\
\cline { 2 - 8 } Item & $1(379)$ & $3(369)$ & $7(370)$ & $8(366)$ & & & \\
number & $\mathrm{B}$ & $\mathrm{D}$ & $\mathrm{H}$ & $\mathrm{B}$ & Min & Max & Diff. \\
\hline $\mathbf{( . . ) 1 2}$ & 81.0 & 93.0 & 87.8 & 80.9 & 80.9 & 93.0 & 12.1 \\
A01 & 73.6 & 79.7 & 79.5 & 73.0 & 73.0 & 79.7 & $6.7^{*}$ \\
A02 & 89.4 & 88.1 & 85.7 & 85.2 & 85.2 & 89.4 & 4.2 \\
A03 & 90.0 & 90.5 & 88.1 & 89.9 & 88.1 & 90.5 & 2.4 \\
A04 & 70.7 & 68.6 & 71.9 & 72.7 & 68.6 & 72.7 & 4.1 \\
* significant at the 5\% level (two-tailed). & & & &
\end{tabular}


If four student groups are totally equivalent, then their performance on any item should not differ significantly. Of course one group could by chance contain a large number of "extreme" students, and thus display a different performance pattern, but with the large sample size in TIMSS and TIMSS-R this chance is minimal. The results on the items A02, A03 etc also show that the groups performed at comparable levels, as can be seen in Tables $7 \mathrm{a}$ and $7 \mathrm{~b}$. Not one of the groups outperformed the others on these items. It was only on item A01 where the disturbance occurred.

The difference in performance moves correspondingly to the difference in performance on the predecessor. The groups 1 and 8 receive a more difficult predecessor item and perform lower than their counterparts. The passage from the predecessor item to the common item A01 is illustrated in Figures 4a and 4b, which are a zoom on the cluster passage of Figures 3a and $3 b$.

As can be seen, higher performances on the predecessor, generally leads to higher performance on the next item. Or reversely: a difficult predecessor item seems to lower the performance of the next item.

Figure 4a.

P-values by four TIMSS student groups on the passage from a different item towards the common items.

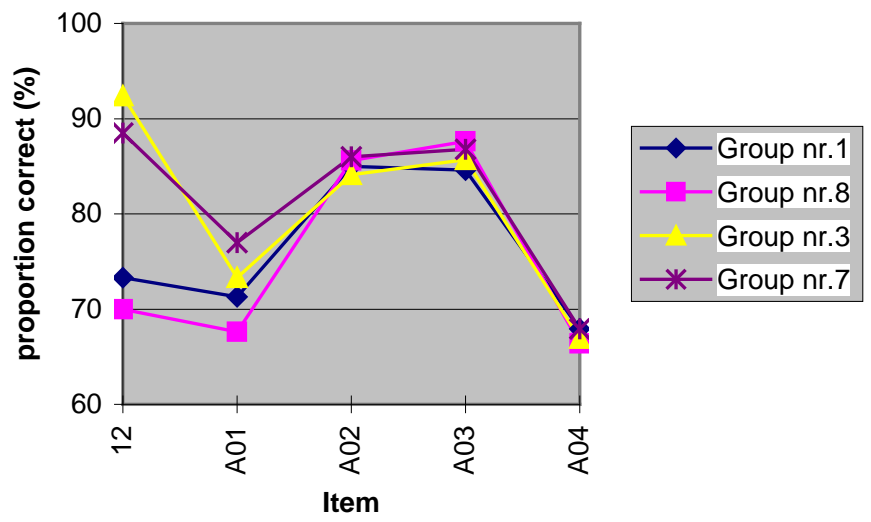

Figure 4b.

P-values by four TIMSS-R student groups on the passage from a different item towards the common items.

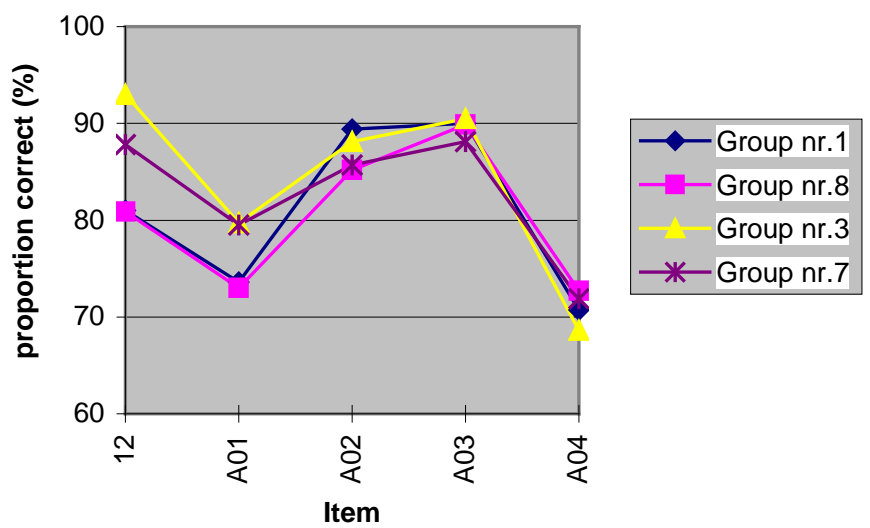




\section{Conclusion}

The study that is presented in this paper shows that the performances on an item in a cognitive test can be higher or lower, depending on the predecessor item in the item sequence. It shows that a test is not a union of single items, but a linear sequence of items. The sequence prior to an item is a component of the testing environment. Especially if students receive a difficult item with only small numbers of students being successful, the performance on the ensuing item is disturbed. It seems that working on a difficult item has an emotional effect, which affects the performance immediately thereafter.

According to the data in this study, the predecessor effect does not last long. The disturbance occurs only on one item and has faded on the ensuing items.

This study supports the practice of ordering items in a cognitive from "easy to hard", as is generally recommended (Wood, 1991). With this method the harder items will have a smaller effect on the other items. Any classroom teacher knows from practice that a puzzling question at the beginning of a test will drag down the whole class result.

In this study the Dutch databases of the TIMSS and TIMSS-R achievement test were used. But TIMSS was not specifically designed for a study on item sequencing. It was a lucky circumstance (for the analyses reported here) that the incomplete test design of TIMSS offered an opportunity. Because of the mixing of difficulty levels and topics in the item clusters, there were distinctive predecessor items for different student groups. If the test items in TIMSS would show less diffusion, this study would not have yielded results. In fact, it would not have taken place.

\section{Discussion}

This present study provides few answers and raises many questions. Below five points will be discussed shortly.

1. Generalisations. To draw generalising conclusions from this study would require further study. Data from the TIMSS and TIMSS-R achievement test were used, which have their limitations for practical reasons. The items concerned were mathematics multiple-choice items. No open-ended questions or higher order tasks were involved in this study. Nor were other subject areas than mathematics considered. As the study was limited to Dutch 14-year-old students, it is unanswered whether the issue also applies to students from other ages and other countries. Would younger students be differently affected? Would students from Asian countries be differently affected?

2. Specialisations. This study was conducted on four samples of 14-year-old Dutch students from 1995 and 1999. It does not differentiate for students' backgrounds. New studies would extend our knowledge on testing behaviour of different segments of student groups. Maybe girls would sustain a different predecessor influence than boys. And maybe students from different socio-economic backgrounds would show differences, too.

3. Test Curriculum Matching Analysis. Within TIMSS a Test Curriculum Matching Analysis (TCMA) was carried out (Beaton, et al., 1996). All test items were scrutinised by curriculum specialists of each participating nation to see whether the 
test items matched the national curriculum of the target population. The non-matching items were deleted and then performance analyses were made.

When looking at the item sequence, these non-matching items are predecessor items to other items, unless they are the very last item in the test. These "unfamiliar" items might be difficult for the students and have a disturbing effect on the performances on the successor items. They can pull down the scores of the successor, even if the latter is in accordance with the curriculum. With this predecessor effect, it is advisable in TCMA that the items that do not match the curriculum should be deleted, but also the ensuing test items. By doing so, the disturbance by unfamiliar items on its environment is minimised.

4. Item Response Theory. The principal method in which student achievement is reported in TIMSS is through scale scores derived using Item Response Theory scaling (Beaton, et al., 1996). With this approach, the performance of a sample of students is summarised on a common scale even when different students have been administered different items. The proficiency scale scores assigned to each student are random draws from the estimated ability distribution of students with similar item response patterns and background characteristics. Maximum likelihood estimates are calculated for the performance of the student on a set of items. The computation of these scores takes into account the varying difficulty of the items across test booklets, and the performance and ability of the students responding to each set of items.

This present study asserts that a set of items cannot be isolated from its predecessor items. It is advised that the difficulty levels of predecessor items be incorporated into the proficiency scale scores.

5. Scale Anchoring. In the international TIMSS-R reports the proficiency of the scale groups of students (at the $25^{\text {th }}, 50^{\text {th }}, 75^{\text {th }}$ and $90^{\text {th }}$ percentile) will be described (TIMSS-R, in preparation). The levels of knowledge and skills of the distinctive groups are summarised by the typical cognitive content of the items that created the distinction between the groups. This study presented in this paper claims that any test item is not an object in itself. An item does not only ask for knowledge and skills, but it also requires a fair testing environment providing for mental stability. Describing scale groups by isolated items does not do justice to the sequence in which they came. An item might be chosen wrongfully to describe the proficiencies of a certain scale group, while in fact its predecessor item created the difference. 


\section{References}

Adams, R.J., \& E.J. Gonzalez (1996). The TIMSS test design. In M.O. Martin \& E.L. Kelly (Eds.), Third International Mathematics and Science Study Technical Report. Volume I: Design and development. Boston, MA: Boston College.

Beaton, A.E., Mullis, I.V.S., Martin, M.O., Gonzales, E.J., Kelly, E.L., \& Smith T.A. (1996). Mathematics achievement in the middle school years. IEA's Third International Mathematics and Science Study. Boston, MA: Boston College.

Bos, K.Tj. \& Vos, F.P. (in preparation). TIMSS-R national Report, The Netherlands. Enschede: OCTO.

Carlson, J.L., \& Ostrosky, A.L. (1992). Item sequence and student performance on multiple-choice exams: Further evidence. Journal of Economic Education, 23 (3), 232-35.

Huck, S.W., \& Bowers, N.E. (1972). Item difficulty level and sequence effects in multiple-choice achievement tests. Journal of Educational Measurement, 9 (2), 105111.

Hodson, E. (1984). The effect of changes in item sequence on student performance in a multiple-choice chemistry test. Journal of Research in Science Teaching, 21 (5), 489-495.

Hodson, E. (1987). How important is question sequence? Education in Chemistry, 24, 11-22.

Kuiper, W.A.J.M., Bos, K.Tj., \& Plomp, Tj. (1997). Wiskunde en de natuurwetenschappelijke vakken in leerjaar 1 en 2 van het voortgezet onderwijs. Nederlands aandeel in TIMSS populatie 2 [Mathematics and the science domains in secondary 1 and 2. Dutch participation in TIMSS population 2]. Enschede: University of Twente, OCTO.

Kuiper, W.A.J.M., Bos, K.Tj., \& Plomp, Tj. (1999). Mathematics achievement in the Netherlands and appropriateness of the TIMSS mathematics test. Educational Research and Evaluation, 5 (2), 85-104.

Kuiper, W.A.J.M., Bos, K.Tj., \& Plomp, Tj. (2000). The TIMSS national option test. Studies in Educational Evaluation, 26 (2000), 43-60.

Wood, R. (1991). Assessment and testing. Cambridge: Cambridge University Press.

TIMSS-R (in preparation). Third International Mathematics and Science Study - 1999 (TIMSS-R). Volume !: Mathematics. Boston: International Study Center TIMSS-R. 